\title{
HAEMATOLOGICAL PROFILE OF PREGNANT WOMEN INFECTED WITH MALARIA PARASITES AT FEDERAL TEACHING HOSPITAL ABAKALIKI, EBONYI STATE
}

\author{
${ }^{1}$ Alo Moses Nnnaemeka, ${ }^{2}$ Okonkwo Eucharia Chinyere, \\ ${ }^{3}$ Anyim Chukwudi and ${ }^{4}$ I. Ugah Uchenna \\ ${ }^{1}$ Department of Microbiology, Federal University, Ndufu-Alike Ikwo, Ebonyi State, Nigeria \\ ${ }^{2}$ Department of Applied Microbiology, Ebonyi State University, Abakaliki, Ebonyi State, Nigeria \\ ${ }^{3}$ Department of Applied Microbiology and Brewing, Nnamdi Azikiwe University, Awka, Nigeria \\ ${ }^{4}$ Department of Medical Biochemistry, Federal University, Ndufu-Alike Ikwo, Ebonyi State, Nigeria
}

Received 2014-05-13; Revised 2014-06-06; Accepted 2014-07-16

\begin{abstract}
Malaria in pregnancy is a major public health problem in endemic areas of sub-Saharan Africa and has important consequences on birth outcome. There are subtle and substantial changes in hematological parameters of malaria in pregnancy. This work is designed to ascertain the impact of malaria in pregnant women visiting Federal Teaching Hospital Abakaliki II. Out of the 100 pregnant women screened for malaria, $44(44.0 \%)$ were positive for malaria parasite. Of the $44.0 \%$ pregnant women positive for malaria parasite, the age range of 26-30 years (31.8\%) were more infected with malaria parasite, followed by 21-25 years (22.7), while 41-45 (4.5\%) years were the least infected. Pregnant women with no formal education were most infected (36.4\%), followed by primary education (27.3\%), while secondary education showed the lowest rate of malaria in pregnancy (13.6\%). Housewives reported the highest cases of malaria in pregnancy, while student reported the lowest $(9.2 \%)$. Married women showed the highest cases of malaria in pregnancy (79.5\%), while widow reported the lowest (2.3). Christian reported in the highest cases of pregnancy in malaria (46.0\%) and Muslim the least $(40.0 \%)$. The mean values of the haematological parameters of pregnant women with respect to parasitaemia were Heamoglobin $(9.78 \pm 37.45 \mathrm{~g} / \mathrm{dL})$, Packed cell volume $(31.56 \pm 2721.14 \%)$, White blood count $\left(8.58 \pm 50.06 \times 10^{3} / \mathrm{mm}^{2}\right)$, Neutrophils $(57.96 \pm 1004.97 \%)$, Lymphocyte $(28.24 \pm 1392.97 \%)$, Mesophils $(7.28 \pm 110.49 \%)$, Eosinophils $(3.62 \pm 1156.91 \%)$ and Platelets $\left(141.88 \pm 133873.07 \times 10^{9} / 1\right)$. This study have shown that the adverse consequences of malaria in pregnancy has great impact on heamatological parameters which may affect not only the neonate and infant but also increase the risk of non communicable diseases when the child grows into an adult and the risk of low birth weight in the next generation.
\end{abstract}

Keywords: Malaria, Haematological Profile, Pregnant Women, Abakaliki

\section{INTRODUCTION}

Malaria is widespread in tropical and subtropical regions in a broad band around the equator, including much of Sub-Saharan Africa, Asia and the Americas. Five species of Plasmodium can infect and be transmitted by humans. The vast majority of deaths are caused by $P$.falciparum while $P$.vivax, P. ovale and
$P$. malariae cause a generally milder form of malaria that is rarely fatal (Beare et al., 2006).

It has been recognized for nearly a century that pregnant women are especially prone to severe malaria (Nayak et al., 2009). Approximately 50 million pregnant women are exposed to malaria each year (Gamble et al., 2009). The burden of Malaria In Pregnancy (MIP) remains high in endemic areas, where despite Corresponding Author: Alo Moses Nnnaemeka, Department of Microbiology, Federal University, Ndufu-Alike Ikwo, Ebonyi State, Nigeria 
considerable immunity, pregnant women continue to have symptomatic and asymptomatic parasitaemia resulting in adverse pregnancy outcomes (Olukemi et al., 2011). Malaria and pregnancy usually affect the course of each other adversely. The physiological changes of pregnancy and pathological changes due to malaria have a deleterious effect on the course of each other. In endemic areas, clinical episodes of malaria are more frequent and more severe during pregnancy and mortality rate is higher among them as compared to nonpregnant (Ramsay, 2003).

Many studies from areas with different malaria transmission patterns have investigated the consequences of malaria in pregnancy on both maternal health and birth outcomes (DeBeaudrap et al., 2013). Malaria in pregnancy has been associated with significant degree of intrauterine growth restriction, 36\% of preterm deliveries, $30 \%$ of preventable low birth weight deliveries, $14 \%$ of low birth weight deliveries and $15 \%$ of maternal anaemia (Steketee et al., 2001). While the consequences of MIP on maternal health are dominated by anaemia, data on malaria-related maternal mortality are sparse (Desai et al., 2007).

The World Health Organization recommends the use of Intermittent Presumptive Treatment with sulphadoxine pyrimethamine (IPTsp), household use of Insecticide Treated Nets (ITNs) and effective and prompt case management as malaria control strategies in pregnancy (WHO, 2012). In areas of stable malaria transmission in sub-Saharan Africa, ITNs are highly effective in reducing childhood mortality and morbidity frommalaria (Lengeler, 2004). Although ITNs are being promoted as a major tool in the fight against malaria in pregnancy, the available evidence about their effect in pregnancy appears inconsistent (Gamble et al., 2009). Other malaria control measures recommended include personal protection measures against vectors such as use of residual sprays, window screening and mosquito repellent creams. In Nigeria, traditional remedies against malaria have always been employed, though with unproven efficacy, while chemoprophylaxis with weekly pyrimethamine and chloroquine which were widely utilized in several African countries are no longer efficacious because of emergence of resistance (WHO, 2013; Nahlen et al., 2012; Sirima et al., 2003).

Despite numerous studies conducted over the last decades, Malaria In Pregnancy (MIP) remains an important public health problem that has proved difficult to tackle (DeBeaudrap et al., 2013). The relationship between malaria in pregnancy and its outcome on birth in endemic areas such as Nigeria continues to be a subject of research. Hence this present work is carried out to ascertain the haematological profile of pregnant women infected with malaria parasites at Federal Teaching Hospital Abakaliki, Ebonyi State.

\section{MATERIALS AND METHODS}

\subsection{Study Area}

The study was carried out at Federal Teaching Hospital Abakaliki II (FETHA II), Ebonyi State. The study area is located between Latitude $06^{\circ} 4^{\prime} \mathrm{N}$ and longitude $08^{\circ} 5^{\prime} \mathrm{E}$ and rainfall pattern is bimodal (AprilJuly), September-November with a short spell sometimes in August. The annual rainfall is between 1000-1500 $\mathrm{mm}$. The vegetation of the area is predominantly derived Savannah. The mean annual temperature is about $24^{\circ} \mathrm{C}$ and the relative humidity is between $60-80 \%$.

\subsection{Study Population}

A total of 100 pregnant women were randomly selected from FETHA II between December, 2013 and March, 2014. The sample population was selected irrespective of age, level of education, marital status, occupation and religion.

\subsection{Ethical Consideration}

Consent was also obliged and obtained from the husbands of the pregnant women. Informed consent was also obtained from all study subjects. Ethical clearance was obtained from Federal Teaching Hospital Abakaliki II (FETHA II), Ebonyi State.

Semi-structured questionnaires were administered to obtain vital information such as age, level of education, marital status and religion.

\subsection{Blood Collection, Staining and Microscopy}

Two milliliter of blood was collected intravenously under a sterile condition. The blood samples were put in EDTA bottles, labeled and sent to Department of Medical Laboratory Science Laboratory, Ebonyi State University, Abakaliki, where thick was prepared and stained with $10 \%$ Giemsa as described by Ochei and Kolhatkar (2007). The blood films were examined microscopically using $40 \times$ and $100 \times$ objectives (with oil immersion) and $7 \times$ eye piece.

\subsection{Complete Blood Count}

Complete Blood Count (CBC) absolute count of white blood cell (total and differential), heamoglobin estimation, 
platelets and lymphocyte where determined using an automated full counter (Abacus Junior Analyzer).

\subsection{Statistical Analysis}

Percentage, mean and Standard Deviation (SD) were used to analyze data obtained in this study.

\section{RESULTS}

Out of the 100 pregnant women screened for malaria parasite, $44(44.0 \%)$ pregnant women were positive for malaria parasite as shown in Table 1.

Out of the 44 pregnant women positive for malaria parasite (as shown in Table 1), the age range of 26-30 years were more infected with malaria parasite 14 (31.8\%), followed by $21-25$ years age range $10(22.7 \%)$, while pregnant women within the age range of 41-45 years were the least infected with malaria parasite 2 (4.5\%). The level of education of the pregnant women with respect to infection of malaria parasite showed that pregnant women with no formal education were most infected with malaria parasite $16(36.4 \%)$, followed by primary education $12(27.3 \%)$, while secondary education showed the lowest rate of malaria in pregnancy $6(13.6 \%)$ as shown in Table 2.

With respect to occupation, housewives reported the highest cases of malaria in pregnancy $13(29.5 \%)$, followed by petty traders $11(25.0 \%)$, civil servants 10 $(22.7 \%)$, casual labourers $6(13.6 \%)$, students reported the lowest $4(9.2 \%)$ as shown in Table 3. In terms of marital status, married women reported the highest cases of malaria in pregnancy $35(79.5 \%)$, followed by unmarried women $5(11.4 \%)$, divorced/separated 3 $(6.8 \%)$ and widow reported the lowest $1(2.3 \%)$ as shown in Table 4. With respect to religion, Christians reported the highest case of malaria in pregnancy 33 $(75.00 \%)$ and Muslim the least $11(25.0 \%)$.

The haematological parameters (heamoglobin, packed cell volume, white blood count, neutrophils, lymphocytes, mesophils, eosinophils, basophils and platelets) of the pregnant women attending FETHA II were also ascertained as shown in Table 4.

\section{DISCUSSION}

Malaria remains a major public health problem in sub Saharan Africa and the extent of utilisation of malaria preventive measures may impact on the burden of malaria in pregnancy (Tongo et al., 2011). Pregnant women are more susceptible to malaria than their non- pregnant counterparts (Boel et al., 2012). Maternal, placental or foetal malaria infection during pregnancy adversely affects development and survival of foetus through low birth weight, maternal anemia and possibly abortion and stillbirth. These malaria induced medical problems constitute major clinical, public health and research challenges (Murphy and Breman, 2001). This infection can aggravate other infections; dual infection has additional detrimental effects on maternal and infant survival (Ticconi et al., 2003). Malaria also remains the preventable cause of low birth weight deliveries worldwide (Saba et al., 2008). Despite numerous studies conducted over the last decades, Malaria in Pregnancy (MiP) remains an important public health problem that has proved difficult to tackle (DeBeaudrap et al., 2013).

A total of 100 women were enrolled for this study, of which $44.0 \%$ were positive for malaria infections detected by thick film as shown in Table 1 . The result obtained in this work is higher than the prevalence rate of $28.0 \%$ observed in Mbarara District, Southwestern Uganda by DeBeaudrap et al. (2013).

Most of the pregnant women within the age range of 26-30 years were more infected with malaria parasite $(31.8 \%)$, followed by $21-25$ years age range $(22.7 \%)$, while pregnant women within the age range of 41-45 years were the least infected with malaria parasite $(4.5 \%)$ as shown in Table 1. This is in line with the work of Matthew et al. (2013) who reported that MiP mostly occurred between the age range of 20-29 years $(48.0 \%)$.

The rate of Malaria in Pregnancy (MiP) in association with occupation, it is notice that most of the study population with MiP were mostly the housewives (29.5\%), followed by petty traders $(25.0 \%)$, civil servants $(22.7 \%)$, casual labourers (13.6\%), while students (9.2\%) the least (Table 2). This work is similar to that reported by Matthew et al. (2013) where occupations of pregnant women are mostly as full-time housewives (54.0\%).

Table 1. Prevalence of malaria parasite in pregnancy with respect to demographic data (age)

\begin{tabular}{lcl}
\hline $\begin{array}{l}\text { Age range } \\
\text { (yeasrs) }\end{array}$ & $\begin{array}{l}\text { Number } \\
\text { examined }\end{array}$ & $\begin{array}{l}\text { Number } \\
\text { positive }(\%)\end{array}$ \\
\hline$<21$ & 10 & $4(9.2)$ \\
$21-25$ & 21 & $10(22.7)$ \\
$26-30$ & 30 & $14(31.8)$ \\
$31-35$ & 16 & $8(18.2)$ \\
$36-40$ & 13 & $6(13.6)$ \\
$41-45$ & 10 & $2(4.5)$ \\
Total & 100 & $44(44.0)$ \\
\hline
\end{tabular}


A well-known risk factor for Malaria in Pregnancy (MiP) is level of education (Steketee et al., 2001; Desai et al., 2007). Malaria in Pregnancy (MiP) was recorded highest in pregnant women with no formal education $(36.4 \%)$, followed by those who attended primary schools only $(27.3 \%)$, higher institution $(22.7 \%)$, this was followed by prevalence of malaria among pregnant women that had secondary education were recorded the lowest (13.6\%) (Table 3). Hence low education levels were dependently associated with malaria during pregnancy in FETHA II. These findings further support the notion that it is essential to scale up malaria prevention efforts in more isolated and deprived communities as recently highlighted in a meta-analysis of datasets from 25 African countries (Eisele et al., 2012). Similarly, reported that most infected with malaria infection were the pregnant women that had secondary education (38.0\%), followed by those with adult literacy $(30.0 \%)$; which is likely to be those no formal education in this study).

Table 2. Prevalence of malaria parasite in pregnancy with respect to demographic data (level of education)

\begin{tabular}{lcl}
\hline $\begin{array}{l}\text { Level of } \\
\text { education }\end{array}$ & $\begin{array}{l}\text { Number } \\
\text { examined }\end{array}$ & $\begin{array}{l}\text { Number } \\
\text { positive }(\%)\end{array}$ \\
\hline No formal education & 38 & $16(36.4)$ \\
Primary & 25 & $12(27.3)$ \\
Secondary & 16 & $6(13.6)$ \\
Higher Institution & 21 & $10(22.7)$ \\
Total & 100 & $44(44.0)$ \\
\hline
\end{tabular}

Table 3. Prevalence of malaria parasite in pregnancy with respect to demographic data (occupation)

\begin{tabular}{lcl}
\hline \multicolumn{3}{c}{ respect to demographic data (occupation) } \\
Occupation & $\begin{array}{l}\text { Number } \\
\text { examined }\end{array}$ & $\begin{array}{l}\text { Number } \\
\text { positive }(\%)\end{array}$ \\
\hline Housewife & 25 & $13(29.5)$ \\
Civil servant & 23 & $10(22.7)$ \\
Petty trader & 21 & $11(25.0)$ \\
Student & 14 & $4(9.2)$ \\
Casual labourer & 17 & $6(13.6)$ \\
Total & 100 & $44(44.0)$ \\
\hline
\end{tabular}

Table 4. Prevalence of malaria parasite in pregnancy with respect to demographic data (marital status)

\begin{tabular}{lcl}
\hline Marital status & $\begin{array}{l}\text { Number } \\
\text { examined }\end{array}$ & $\begin{array}{l}\text { Number } \\
\text { positive }(\%)\end{array}$ \\
\hline Married & 66 & $35(79.5)$ \\
Unmarried & 10 & $5(11.4)$ \\
Divorced/separated & 15 & $3(6.8)$ \\
Widow & 9 & $1(2.3)$ \\
Total & 100 & $44(44.0)$ \\
\hline
\end{tabular}

With respect to religion of MiP, Christians (75.0\%) were the highest of MiP and Muslim the least $(25.0 \%)$. This is result is associated with religion (Christianity) of the most of the people in Abakaliki Metropolis (Table 5).

Pregnancy causes significant changes in metabolism, fluid balance, organ function and blood circulation which are driven by estrogen and the presence of the fetoplacental unit.

These dramatic changes influence a wide variety of hematological parameters. Acknowledge of these changes is essential when interpreting the result of hematological investigation to diagnose or monitor illness pregnant woman (Elgari, 2013).

With respect to marital status of $\mathrm{MiP}$, married pregnant women were the highest of $\mathrm{MiP}(79.5 \%)$, followed by unmarried $(11.4 \%)$ while widow recorded the least $(2.3 \%)$ as shown in Table 4.

Table 5. Prevalence of malaria parasite in pregnancy with respect to demographic data (religion)

\begin{tabular}{lll}
\hline Religion & Number examined & Number positive $(\%)$ \\
\hline Christianity & 72 & $33(46.0)$ \\
Muslim & 28 & $11(40.0)$ \\
Total & 100 & $44(44.0)$ \\
\hline
\end{tabular}

Table 6. Haematological parameters of pregnant women with respect to parasitaemia

\begin{tabular}{ll}
\hline Parameters & Mean values \\
\hline Heamoglobin $(\mathrm{g} / \mathrm{dL})$ & $9.78 \pm 37.45$ \\
Packed cell volume $(\%)$ & $31.56 \pm 2721.14$ \\
White blood count $\left(\times 10^{3} / \mathrm{mm}^{2}\right)$ & $8.58 \pm 50.06$ \\
Neutrophils $(\%)$ & $57.96 \pm 1004.97$ \\
Lymphocyte $(\%)$ & $28.24 \pm 1392.97$ \\
Mesophils $(\%)$ & $7.28 \pm 110.49$ \\
Eosinophils $(\%)$ & $3.62 \pm 1156.91$ \\
Basophils $(\%)$ & 0 \\
Platelets $\left(\times 10^{9} / 1\right)$ & $141.88 \pm 133873.07$ \\
\hline
\end{tabular}

Values were mean \pm Standard Deviation (SD)

Table 7. Mean haematological parameters

\begin{tabular}{ll}
\hline Parameters & Mean values \\
\hline Heamoglobin $(\mathrm{g} / \mathrm{dL})$ & $\geq 11$ \\
Packed cell volume $(\%)$ & $38.75 \pm 3.70$ \\
White blood count $\left(\times 10^{3} / \mathrm{mm}^{2}\right)$ & $4.93 \pm 0.90$ \\
Neutrophils $(\%)$ & $44.63 \pm 13.4$ \\
Mesophils $(\%)$ & $44.86 \pm 12.50$ \\
Eosinophils $(\%)$ & $6.32 \pm 3.40$ \\
Basophils $(\%)$ & $1.30 \pm 0.52$ \\
Platelets $\left(\times 10^{9} / \mathrm{l}\right)$ & $260.0 \pm 66.0$ \\
\hline Values were mean \pm Standard Deviation (SD) &
\end{tabular}


The World Health Organization has suggested that anemia is present in pregnancies when $\mathrm{Hb}$ concentration is less than $11 \mathrm{~g} / \mathrm{dL}$ (Milman et al., 2007). The study revealed significant decreases in haemoglobin $(9.78 \pm 37.45 \mathrm{~g} / \mathrm{dL})$, packed cell volume $(31.56 \pm 2721.14 \%)$ and platelets $(141.88 \pm 133873.07$ $\left.\times 10^{9} / 1\right) \quad($ Table 6$)$ respectively of pregnant women compared to the control (Table 7). However, mean numeric values for most of the hematological profiles were below the normal range values for pregnant women reported (Abbassi-Ghanavati and Greer, 2010).

The findings of this work are consistent with previous study which reported that the decreases in hemoglobin and packed cell volume concentration are common findings during pregnancy and results from increased plasma volume combined poor iron intake (Bashiri et al., 2003; Ruchi et al. 2013; Elgari, 2013).

The decrease in PCV ascertained in this work, may be due to increase in plasma volume during pregnancy. Hence there is need for adequate management of their blood profiles with dietary supplementation. A study showed marked decrease in PCV in the third trimester of pregnancy might be attributed to maternal diabetes (Pilsczek et al., 2008).

Significant decreases in platelet count of out pregnant women obtained in this work compared to control in agreement with study reported that: Although platelet counts remain in the normal pregnant range in most women during uncomplicated pregnancies (Matthews et al., 1990). Mean platelet counts of pregnant women may be slightly lower than in healthy non pregnant women (Verdy et al., 1997).

White blood cells are responsible for body defense. During pregnancy, WBC is reported to be elevated (Pitkin and Witte, 1979). We found significant increased in white blood count $(8.58 \pm 50.06 \%$ $\left.\times 10^{3} / \mathrm{mm}^{2}\right)$, neutrophils $\quad(57.96 \pm 1004.97 \%)$, lymphocytes $\quad(28.24 \pm 1392.97 \%), \quad$ mesophils $(7.28 \pm 110.49 \%)$ and eosinophils $(3.62 \pm 1156.91 \%)$ significant higher compared to that of the controls. The finding in agreement with previous study reported (Rouse et al., 1998). Increase in these haematological parameters may be as a result of the body building the immunity of the fetus and it is achieved by a state of selective immune tolerance, in the presence of a strong antimicrobial immunity (Elgari, 2013). The result of this work agrees with previous work by Roy et al. (2007) that reported a total leukocyte count rising in early pregnancy which remained elevated through pregnancy.

\section{CONCLUSION}

Malaria in Pregnancy (MiP) adversely affects the pregnancy outcome. It is likely to increases the risk of spontaneous abortion, stillbirths, premature delivery and low birth weight. Anaemia (low haemoglobin, $<11 \mathrm{~g} / \mathrm{dL}$ ) in pregnancy is associated with adverse consequences both for the mother and the foetus. This study have shown that the adverse consequences of MiP has great impact on heamatological parameters which may affect not only the neonate and infant but also increase the risk of non communicable diseases when the child grows into an adult and the risk of low birth weight in the next generation.

\section{ACKNOWLEDGEMENT}

We wish to aknoledge the staff of Microbiology Unit, Federal Teaching Hospital Abakaliki II for their assistance during the period of this work.

\section{REFERENCES}

Abbassi-Ghanavati, M. and L.G. Greer, 2010. Reference Table of Normal Laboratory Values in Uncomplicated Pregnancies. In: Williams Obstetrics, Cunningham, F.G., K.J. Leveno, S. Bloom, J.C. Hauth and D.J. Rouse et al. (Eds.), McGraw Hill Professional, New York, ISBN-10: 0071702857, pp: 1404-1404.

Bashiri, A.B., E.E. Sheiner and M. Mazor, 2003. Anemia during pregnancy and treatment with intravenous iron: Review of literature. Eur. J. Obstetric Gynecol. Reproductive Biol., 110: 2-7. PMID: 12932861

Beare, N.A., T.E. Taylor, S.P. Harding, S. Lewallen and M.E. Molyneux, 2006. Malarial retinopathy: A newly established diagnostic sign in severe malaria. Am. J. Tropical Med. Hygiene, 75: 790-797. PMID: 17123967

Boel, M.E., M.J. Rijken, B.J. Brabin, F. Nosten and R. McGready, 2012. The epidemiology of postpartum malaria: Asystematic review. Malaria J., 11: 1-7. DOI: $10.1186 / 1475-2875-11-114$

DeBeaudrap, P., E. Turyakira, L.J. White, C. Nabasumba and B. Tumwebaze et al., 2013. Impact of malaria during pregnancy on pregnancy outcomes in a Ugandan prospective cohort with intensive malaria screening and prompt treatment. Malaria J., 12: 139139. DOI: $10.1186 / 1475-2875-12-139$ 
Desai, M., F.O. Ter Kuile, F. Nosten, R. McGready and K. Asamoa et al., 2007. Epidemiology and burden of malaria in pregnancy. Lancet Infect. Dis., 7: 93-104. PMID: 17251080

Eisele, T.P., D.A. Larsen, P.A. Anglewicz, J. Keating and J. Yukich et al., 2012. Malaria prevention in pregnancy, birth weight and neonatal mortality: A meta-analysis of 32 national cross-sectional datasets in Africa. Lancet Infect. Dis., 12: 942949. PMID: 22995852

Elgari, M.M., 2013. Evaluation of hematological parameters of sudanese pregnant women attending at Omdurman Al Saudi Maternity Hospital. Egypt. Acad. J. Biol. Sci., 5: 37-42.

Gamble, C.L., J.P. Ekwaru and F.O. Kuile, 2009. Insecticide-Treated Nets for Preventing Malaria in Pregnancy (Review). 1st Edn., John Wiley and Sons, Ltd Publication, pp: 38.

Lengeler, C., 2004. Insecticide-treated bed nets and curtains for preventing malaria. Cochrane Database Systematic Rev., 24: 2-2. DOI: 10.1002/14651858

Matthews, J.H., S. Benjamin, D.S. Gill and N.A. Smith, 1990. Pregnancy associated thrombocytopenia: Definition, incidence and natural history. Acta Haematol., 84: 24-24. DOI: 10.1159/000205022

Matthew, A.K., O.O.A. James, D. Bolanle and O.O. Stephen, 2013. Hamatological parameters and malaria parasite infection among pregnant women in Northwest Nigeria. Asian Pacific J. Tropical Dis., 3: 47-50. DOI: 10.1016/S22221808(13)60010-9

Milman, N., T. Bergholt, K. Byg, L. Eriksen and A.M. Hvas, 2007. Reference intervals for haematological variables during normal pregnancy and postpartum in 434 healthy Danish women. Eur. J. Haematol., 79, 39-46. PMID: 17598837

Murphy, S.C. and J.G. Breman, 2001. Gaps in the childhood malaria burden in Africa: Cerebral malaria, neurological sequelae, anemia, respiratory distress, hypoglycemia and complications of pregnancy. Am. J. Tropical Med. Hygiene, 64: 57-67. PMID: 11425178

Nahlen, B.L., T. Alakija, O. Ogunbode, O. Adetoro and A. Akintunde et al., 2012. Lack of pyrimethamine prophylaxis in pregnant Nigerian women. Lancet. 8667: 830-834. DOI: 10.1016/S0140-6736(89)92998-X
Nayak, K.C., M.P. Khatri, B.K. Gupta, P. Sirohi and V. Choudhary et al., 2009. Spectrum of vivax malaria in pregnancy and its outcome: A hospital based study. Vector Borne Dis., 46: 299-302. PMID: 19959857

Ochei, J.O. and A.A. Kolhatkar, 2007. Medical Laboratory Science: Theory and Practice. 1st Edn., Tata McGraw-Hill Publishing Company Limited, New Delhi, New York, USA., pp: 963.

Olukemi, O.T., E.O. Adebola and O.A. Olusegun, 2011. Utilization of malaria preventive measures during pregnancy and birth outcomes in Ibadan, Nigeria. BMC Pregnancy Childbirth. 11: 60-60. DOI: 10.1186/1471-2393-11-60

Pilsczek, F.H., W. Renn, H. Hardin and R.M. Schmülling, 2008. Clinical laboratory values during diabetic pregnancies. J. Ayuba Med. College Abbottabad, 20: 3-6. PMID: 19024174

Pitkin, R.M. and D.L. Witte, 1979. Platelet and leucocyte count in pregnancy. J. Am. Med. Assoc.. 242: 26962698. DOI: 10.1001/jama.242.24.2696

Ramsay, S., 2003. Preventing malaria in pregnancy. Lancet, 3: 4-4. PMID: 12505015

Rouse, D.J., J. Owen and R.L. Goldenberg, 1998. Routine maternal platelet count: An assessment of a echnologically driven screening practice. Am. J. Obstetric Gynecol., 179: 573-573. DOI: 10.1016/S0002-9378(03)00912-8

Roy, L., P.E. Duffy, C. Antony and D.W. Taylor, 2007. Malaria in pregnancy: Pathogenesis and immunity. Lancet Infect. Dis., 7: 105-117. DOI: 10.1016/S1473-3099(07)70022-1

Ruchi, K., B. Pradeep and K. Varun, 2013. A study of erythron status in pregnant and non-pregnant age matched females of Jodhpur. IOSR J. Pharmacy, 3: 35-39.

Saba, N., A. Sultana and I. Mahsud, 2008. Outcome and complications of malaria in pregnancy. Gomal J. Med. Sci., 6: 98-101. DOI: 10.5001/omj.2012.52

Sirima, S.B., R. Sawadogo, A.C. Moran, A. Konate and A. Diarra et al., 2003. Failure of a chloroquine chemoprophylaxis program to adequately prevent malaria during pregnancy in Koupela District, Burkina Faso. Clin. Infect. Dis., 36: 1374-1382. DOI: 10.1086/375077

Steketee, R.W., B.L. Nahlen, M.E. Parise and C. Menendez, 2001. The burden of malaria in pregnancy in malaria-endemic areas. Am. J. Tropical Med. Hygiene, 64: 28-35. DOI: org/10.4236/ojpm.2013.32035 
Ticconi, D., M. Mapfumo, M. Dorrucci, N. Naha and E. Tarira et al., 2003. Effect of maternal HIV and malaria infection on pregnancy and perinatal outcome in Zimbabwe. J. Acquire Immune Deficiency Syndromes, 34: 289-94. DOI: 10.1097/00126334-200311010-00005

Tongo, O.O., A.E. Orimadegun and O.O. Akinyinka, 2011. Utilisation of malaria preventive measures during pregnancy and birth outcomes in Ibadan, Nigeria. BMC Pregnancy Childbirth, 11: 1-7. DOI: 10.1186/1471-2393-11-60
Verdy, E., V. Bessous and M. Dreyfus, 1997. Longitudinal analysis of platelet count and volume in normal pregnancy. Thromb Haemost. 77: 806. DOI: 10.1016/j.amepre.2009.12.018

WHO, 2012. A strategic framework for malaria prevention and control during pregnancy in the African region. World Health Organization.

WHO, 2013. Expert committee on malaria 18th report. World Health Organization. 